\title{
Improving Community Health While Satisfying a Critical Community Need: A Case Study for Nonprofit Hospitals
}

\author{
Alicia M. Hoke, MPH, CHES; Donna K. Kephart, MHA; Judith F. Dillon, MSN, MA, RN;
}

Jody R. McCullough; Barbara J. Blatt, MEd; Jennifer L. Kraschnewski, MD, MPH

\begin{abstract}
Suggested citation for this article: Hoke AM, Kephart DK, Dillon JF, McCullough JR, Blatt BJ, Kraschnewski JL. Improving Community Health While Satisfying a Critical Community Need: A Case Study for Nonprofit Hospitals. Prev Chronic Dis 2015; 12:150230. DOI: http://dx.doi.org/10.5888/pcd12.150230.
\end{abstract}

\section{PEER REVIEWED}

\section{Abstract}

\section{Background}

School-based student health screenings identify issues that may affect physical and intellectual development and are an important way to maintain student health. Nonprofit hospitals can provide a unique resource to school districts by assisting in the timely completion of school-based screenings and meet requirements of the Affordable Care Act. This case study describes the collaboration between an academic medical center and a local school district to conduct school-based health screenings.

\section{Community Context}

Penn State Milton S. Hershey Medical Center and Penn State Hershey PRO Wellness Center collaborated with Lebanon School District to facilitate student health screenings, a need identified in part by a community health needs assessment.

\section{Methods}

From June 2012 through February 2013, district-wide student health screenings were planned and implemented by teams of hospital nursing leadership, school district leadership, and school nurses. In fall 2013, students were screened through standardized procedures for height, weight, scoliosis, vision, and hearing.

\section{Outcomes}

In 2 days, 3,105 students ( $67 \%$ of all students in the district) were screened. Letters explaining screening results were mailed to parents of all students screened. Debriefing meetings and follow-up surveys for the participating nurses provided feedback for future screenings.

\section{Interpretation}

The 2-day collaborative screening event decreased the amount of time spent by school nurses in screening students throughout the year and allowed them more time in their role as school wellness champion. Additionally, parents found out early in the school year whether their child needed physician follow-up. Partnerships between school districts and hospitals to conduct student health screenings are a practical option for increasing outreach while satisfying community needs.

\section{Background}

The concept that healthier students are better learners is supported by leading national education organizations and a wide body of literature $(1,2)$. Given that $91 \%$ of all US adolescents attend school, schools are an ideal setting for delivering services and programs to keep students healthy and ready to learn (3). One important intervention is school-based student health screenings, used by schools to identify potential medical concerns that might affect physical and intellectual development. Most US school districts have policies that require routine screening for vision impairment (90.3\% of school districts) and hearing impairment (91.7\% of school districts) (4). As a potential approach to addressing the childhood obesity epidemic, $18 \%$ of states have also mandated body mass index (BMI) screening in schools $(4,5)$. School-based screening requires a significant effort by school personnel, often the school nurse. In some schools, an entire school year is needed to complete screenings and disseminate results to parents, thereby delaying any action that could correct potential problems. 
Regulations under the Affordable Care Act require nonprofit hospitals to complete community health needs assessments and identify ways to satisfy unmet needs (6). School districts identified through a needs assessment as having unmet needs provide an opportunity for nonprofit hospitals to help.

This case study describes a novel collaboration between a medical center and a neighboring school district, in which hospital nursing leaders assisted in conducting school-based screenings. We propose that nonprofit hospitals are a unique resource to school districts for assistance in conducting school-based screenings (Figure).

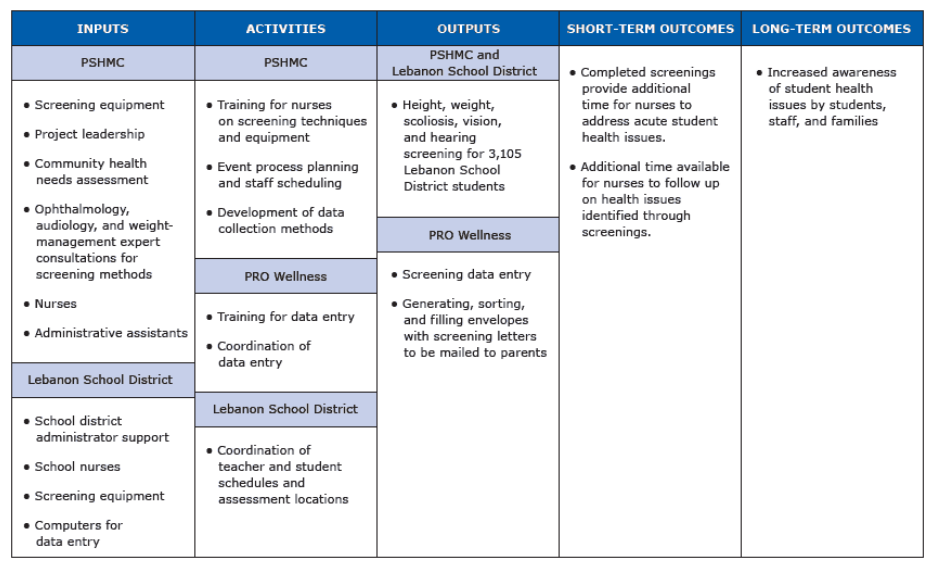

Figure. Logic model describing engagement of involved organizations and implementation of the Lebanon student health screenings, Lebanon, Pennsylvania, 2012-2013. Abbreviations: PSHMC, Penn State Milton S. Hershey Medical Center; PRO Wellness, Penn State Hershey PRO Wellness Center.

\section{Community Context}

A community health needs assessment was conducted in 2011 by a collaborative of hospital systems in Central Pennsylvania. The assessment included Cumberland, Dauphin, Lebanon, Perry, and York counties, all served by the health care systems involved. Assessment data showed that Lebanon county had greater health vulnerabilities than other counties assessed, including higher rates of children living in poverty and single-parent households, obesity, smoking, teen births, and uninsured families and lower proportions of primary care physicians and dentists (7). The needs assessment data correlated with the health rankings of Pennsylvania counties (8), demonstrating the effectiveness of the needs assessment in identifying the needs of the community.
In 2012, Penn State Milton S. Hershey Medical Center (PSHMC) reached out to Lebanon School District, one of the main school districts in Lebanon County, to organize a collaborative effort to respond to the vulnerabilities identified. In this district, $74 \%$ of students were enrolled in the national program for free or reducedprice lunch, and $39 \%$ of students in kindergarten through grade 6 and $38 \%$ of students in grade 7 through grade 12 were overweight or obese $(9,10)$. District nurses and administrators indicated that the length of time required to complete the annual student health screenings was taking away from time needed to manage the acute health needs of students. In addition, the screening process resulted in delays in the dissemination of critical health information to parents and care providers, thereby prolonging or reducing any response to the screening results.

Penn State Hershey PRO Wellness Center (PRO Wellness), an organization committed to educating and inspiring youth and their families to eat well, engage in regular physical activity, and become champions for bringing healthy choices to life, works primarily with schools in Pennsylvania to provide proven interventions and technical guidance in program planning, data collection, and reporting. A natural partnership emerged between PRO Wellness and the PSHMC community benefits team to facilitate student health screenings in Lebanon School District in support of PSHMC's commitment to community activities.

\section{Methods}

Three nonprofit hospitals (PSHMC, PinnacleHealth System, and Holy Spirit Health System) initiated the joint venture to conduct a community health needs assessment of the 5 counties they served. The assessment consisted of 1) interviews of personnel at public and private organizations, such as educational institutions, human services organizations, and faith-based organizations; health professionals; and local government officials; 2) focus groups with key audiences; and 3) community forums (eg, town hall-style meeting). The assessment also used data on disease prevalence, socioeconomic factors, and behavioral habits (7). The assessment identified 3 priority areas: promotion of healthy lifestyles, health education, and access to affordable health care. Lebanon County's health needs were related to health insurance, poor access to health care, overweight and obesity, and health education (7).

The screening initiative was built on an established relationship between PSHMC and PRO Wellness and the Lebanon community. The school district is home to nearly 5,000 students and comprises 5 elementary schools, 1 middle school, and 1 high school. School administrators and nurses identified a hardship in completing the annual student health screenings required by the Pennsylvania Public School Code (11). Nurses from PSHMC and

\footnotetext{
The opinions expressed by authors contributing to this journal do not necessarily reflect the opinions of the U.S. Department of Health and Human Services, the Public Health Service, the Centers for Disease Control and Prevention, or the authors' affiliated institutions.
} 
PRO Wellness staff collaborated on a plan to conduct screening events that met the needs of the district, provided a community education experience for PSHMC nurse leaders, and offered an opportunity to address overweight and obesity among Pennsylvania children, while supporting the needs assessment priority area "promotion of healthy lifestyles."

Planning for the screening events took 1 year (Table) and included several regular meetings between district administrators, school nurses, and project personnel from PSHMC. The following factors were considered: a timeline for training nurses in how to conduct the screenings, availability of screening equipment, and capacity of PSHMC nursing staff. The planning team selected dates for a 2-day screening of students in all 7 district schools. Each school identified a screening location, and the district's technology department established a plan to provide computers and printers in the screening location for entering data into a database and printing parent notification letters.

PSHMC experts in nursing, ophthalmology, audiology, and weight management collaborated with project staff to ensure standard measurement methods and technologies were incorporated into screening plans. A PSHMC nursing team was organized to perform the screenings. Each nurse viewed a standardized 1-hour video, which included a review of anatomy and physiology, and participated in hands-on skills training for each type of screening they would be performing. Training was developed according to Pennsylvania Department of Health screening guidelines (12-15). All hospital personnel who planned to be on-site for the screenings signed a confidentiality form and showed proof of their staterequired criminal background checks.

In December 2012, health screenings for height, weight, scoliosis, vision, and hearing were conducted according to regulations of the Pennsylvania Department of Education (11). PSHMC nurses and school nurses used standardized screening protocols and equipment. Each school's screenings took place during 1 school day; students visited a separate station for each screening, beginning with height and weight measurements (because those are the fastest), and they rotated through stations as stations became available. All screening stations, except for hearing, were set up in the school's gymnasium or auditorium. Hearing screenings were conducted in the school's library to reduce competing noises. To complete all screenings at 1 school in 1 day, 1 nurse was needed for every 50 students.
Elementary and middle school students reported to the screening areas by grade and classroom. For logistical purposes, high school students reported to the screening area alphabetically by last name. Students were given a personalized paper form to carry with them to each station. To ensure student privacy, nurses recorded the screening results on the forms, and all forms were collected before the student exited the screening area. In addition, adequate space was maintained between the student being screened and those waiting in line to be screened; privacy screens were not required or used.

PRO Wellness staff members electronically entered data on height and weight during each screening event, and BMI was calculated automatically in Health eTools software (16). Each student's data were entered using a double data entry check method. Letters notifying parents of their child's BMI were generated through Health eTools (16). Parent letters were printed and placed into pre-addressed envelopes. For vision, hearing, and scoliosis screenings, only parents of students who required a referral were notified by letter, whereas all parents were notified of their child's height, weight, and BMI. To ensure student privacy and compliance with the Family Educational Rights and Privacy Act, the name of the student in the letter was matched to the information printed on the envelope, and all letters were mailed from the school at the completion of each school's screening event (17).

\section{Outcomes}

Annual health screenings were completed for 3,105 students (67\% of all students) from all 7 schools. Parents of each student received screening results early enough in the school year to allow them to take any necessary action. Additionally, school nurses were relieved of a task that typically spanned the length of a school year, creating an opportunity for them to focus on other areas of school health.

Several strategies were used to debrief partners and measure success. School nurses participated in a meeting to discuss the screenings and identified the need for training or guidance materials to assist them in assessing and leading overall wellness initiatives in their school. In addition, the PSHMC nursing team and school nurses were invited to participate in a questionnaire on items such as training, screening methods, adequacy of the screening equipment, and their ability to answer students' questions. A final meeting with district administrators, school nurses, and key project personnel from PSHMC and PRO Wellness was arranged to plan improvements for subsequent screening years.

\footnotetext{
The opinions expressed by authors contributing to this journal do not necessarily reflect the opinions of the U.S. Department of Health and Human Services, the Public Health Service, the Centers for Disease Control and Prevention, or the authors' affiliated institutions.
} 
One unexpected outcome of the screening events was the discovery that $41.5 \%$ of students were overweight or obese, compared with $38 \%$ in previous years (10). Student BMI may have increased, but another possibility is that using standardized screening protocols resulted in more accurate data on height and weight. Additional research is needed to fully explore this possibility.

Several aspects of preparation aided in the success of the screening events and subsequent dissemination of notification letters to parents. These aspects were 1) preprinting and presorting mailing envelopes by classroom, 2) using multiple stations for each type of screening to improve student flow, and 3) having adequate numbers of nurses and staff members available at the screening events. Areas requiring particular attention are 1) assurance that screening equipment is up to date, especially equipment used for screenings that require more time than other screenings (eg, vision), 2) verification that equipment is in working order, 3) calibration of hearing equipment, and 4) use of a stand-alone stadiometer (instead of stadiometer-scale) for measuring height.

Each student age group had its unique challenges. High school students were asked via school intercom to report to the screening area and were unaccompanied by a teacher. This method reduced the number of students who actually reported for their screenings, thereby reducing overall student participation. In addition, high school students were released to the screening location by last name instead of by grade and classroom. Because the software used to enter the screening data and generate parent notification letters organized students by classroom, not by student last name, having high school students arrive alphabetically increased the time required to locate the student in the system, enter the data, generate the letter, and ensure a proper match between the letter and the pre-addressed mailing envelope. Middle school students compared their screening results with their peers, especially their BMI results, creating a potential opportunity for ridicule or bullying. The largest challenge among young elementary school students was their inability to remain quiet during hearing tests. In addition, a language barrier created difficulties in screening students who did not speak fluent English. Many students failed to bring their glasses to the vision test, a common challenge among all age groups.

\section{Interpretation}

Overall, the collaboration with the local school district was successful in completing most required student health screenings in 2 days. Absenteeism, failure to report to the screening area, not having glasses, and language barriers prevented $100 \%$ participation and required school nurses to complete missed screenings at another time. With a large portion of the screenings completed early in the school year, more time was made available for school nurses to address daily acute student health concerns and troubleshoot student health concerns identified by the screenings. Because school nurses spent less time on screening, they had more time to take on the role of school wellness champion. In addition, parents found out earlier in the school year whether their child needed physician follow-up for vision, hearing, scoliosis, or weight-related issues.

Collaboration created the opportunity for addressing health needs in an expanded capacity. It cultivated a trusting relationship between PSHMC and the Lebanon community, thus overcoming a barrier often present between academic medical centers and their surrounding communities (18). Through this collaboration and the discovery of a higher-than-expected rate of overweight and obesity, PSHMC, PRO Wellness, and district administrators planned to extend outreach activities to include school health environment assessments and education on healthy lifestyle choices in addition to annual school screening events. The collaboration also opened up a research opportunity to improve screening methods for hearing. Other collaborative activities now underway are evaluation of the BMI parent notification letter, nutrition and physical activity interventions for students, and school nurse educational conferences.

Although the screening project was largely successful, several items should be considered for future events. Since the inaugural screening event, many of the following suggestions were incorporated as standard practice by the collaboration. First, we suggest that screenings be completed near the beginning of the school year, when absenteeism rates are lower than other times of the year. Screenings scheduled near the December holidays may have contributed to absenteeism. We recommend that data be entered into the database by screening facilitators after, not during, the screening day. Separating the screening event from data entry could increase the number of people available to conduct the screenings and allow for a more streamlined data entry process. This process should include a quality review of data to identify outliers before entry into the database. Special consideration should also be given to how data are recorded during the screening event; the metrics used to record screening data should be consistent with the database used to house the data and the software used to generate parent notification letters (eg, height data recorded as feet and inches or total inches). The order in which the screenings are completed should ensure student privacy. Conducting height and weight screenings last and collecting the completed data forms at that time may decrease the opportunity for students to compare sensitive health information with their peers. We also recommend measuring height and weight behind privacy screens.

The opinions expressed by authors contributing to this journal do not necessarily reflect the opinions of the U.S. Department of Health and Human Services, the Public Health Service, the Centers for Disease Control and Prevention, or the authors' affiliated institutions. 
The screening events also offer an opportunity for health education. While students wait in screening lines, they can be given ageappropriate health education lessons to reinforce the importance of the screenings. Informing students about the purpose of screening may also reduce the possibility of any stigma or bullying related to screening results. In addition, school nurses should be provided resources to champion wellness initiatives, such as tools for assessing their school environment, developing a wellness council, or reviewing and revising wellness policy.

We have described how collaboration between a nonprofit hospital and local school district facilitated the provision of a state-mandated requirement in a timely and efficient manner. The collaborative screening event contributed to accomplishing the community health needs assessment's priority of "promotion of a healthy lifestyle," thereby creating a win-win situation for both the school district and medical center. In addition, the higher-thanexpected rates of overweight and obesity found by the screening process opened doors for additional community-engaged research on this public health concern. Partnerships between school districts and nonprofit hospitals to conduct required student health screenings are a practical option for increasing community outreach while satisfying critical community needs.

\section{Acknowledgments}

The authors thank PSHMC nursing leadership and the Lebanon School District for their partnership in completing the screenings and InnerLink for its technical support during screening events. The authors also thank the Highmark Foundation for its support of the PRO Wellness Center in its role in the screenings.

\section{Author Information}

Corresponding Author: Alicia M. Hoke, MPH, CHES, Penn State Hershey PRO Wellness Center, Penn State College of Medicine, 90 Hope Dr, MC A145, Hershey, PA 17033. Telephone: 717-5311440 ext. 7. Email: ahoke1@hmc.psu.edu.

Author Affiliations: Donna K. Kephart, Penn State Hershey PRO Wellness Center, Penn State College of Medicine, Hershey, Pennsylvania; Judith F. Dillon, Penn State Hershey Medical Center, Hershey, Pennsylvania; Jody R. McCullough, Barbara J. Blatt, Jennifer L. Kraschnewski, Penn State College of Medicine, Hershey, Pennsylvania.

\section{References}

1. Health and academics. Atlanta (GA): US Department of Health and Human Services, Centers for Disease Control and Prevention, National Center for Chronic Disease Prevention and Health Promotion, Division of Population Health; 2015. http://www.cdc.gov/healthyYouth/health_and_academics/. Accessed March 25, 2015.

2. Castelli DM, Hillman CH, Buck SM, Erwin HE. Physical fitness and academic achievement in third- and fifth-grade students. J Sport Exerc Psychol 2007;29(2):239-52.

3. Health and academics. Atlanta (GA): US Department of Health and Human Services, Centers for Disease Control and Prevention, National Center for HIV/AIDS, Viral Hepatitis, STD, and TB Prevention, Division of Adolescent and School Health; 2015. http://www.cdc.gov/healthyyouth/about/ index.htm. Accessed September 21, 2015.

4. Centers for Disease Control and Prevention. Results from the School Health Policies and Practices study 2012. Atlanta (GA): US Department of Health and Human Services; 2013.

5. Nihiser AJ, Lee SM, Wechsler H, McKenna M, Odom E, Reinold C, et al. BMI measurement in schools. Pediatrics 2009;124(Suppl 1):S89-97.

6. Internal Revenue Service. Internal Revenue Bulletin: 2011-30. Notice and request for comments regarding the community health needs assessment requirements for tax-exempt hospitals. 2011. http://www.irs.gov/irb/2011-30_IRB/ar08.html. Accessed September 9, 2015.

7. Community health needs assessment for five south central Pennsylvania counties: executive report. Holy Spirit Health System, Penn State Milton S. Hershey Medical Center, PinnacleHealth System;2012. http:// www.pennstatehershey.org/c/document_library/ get_file?uuid=fdf 21 ea $7-7 \mathrm{dfc}-4$ b $3 \overline{5}-$ b 747 a9fa8904a674\&groupId=10100. Accessed March 25, 2015.

8. County health rankings 2012: Pennsylvania. Madison (WI): University of Wisconsin Population Health Institute; 2012. http://www.countyhealthrankings.org/sites/default/files/states/ CHR2012_PA.pdf. Accessed March 25, 2015.

9. Building data report (lunches only) for October 2011. Harrisburg (PA): Pennsylvania Department of Education; 2013.

10. Growth screens and BMI-for-age percentile. Harrisburg (PA): Pennsylvania Department of Health; 2011.

11. Pennsylvania Public School Code of 1949, Article XIV, § 1402.

12. Procedures for the growth screening program for Pennsylvania's school-age population. Harrisburg (PA): Pennsylvania Department of Health; 2011.

The opinions expressed by authors contributing to this journal do not necessarily reflect the opinions of the U.S. Department of Health and Human Services, the Public Health Service, the Centers for Disease Control and Prevention, or the authors' affiliated institutions. 
13. Guidelines for the school hearing screening program for Pennsylvania's school-age population. Harrisburg (PA): Pennsylvania Department of Health; 2011.

14. Pennsylvania school scoliosis screening program administrative guidelines for school personnel. Harrisburg (PA): Pennsylvania Department of Health; 2011.

15. Procedures for the vision screening program for Pennsylvania's school-age population. Harrisburg (PA): Pennsylvania Department of Health; 2011.

16. Health eTools for schools. Lancaster (PA): InnerLink, Inc. http://www.theinnerlink.com/etools.php. Accessed April 16, 2015.

17. Family Educational Rights and Privacy (FERPA) Act, 20 USC $\S 1232 \mathrm{~g} 34$ CFR Part 99 (1974).

18. Wallerstein NB, Duran B. Using community-based participatory research to address health disparities. Health Promot Pract 2006;7(3):312-23.

The opinions expressed by authors contributing to this journal do not necessarily reflect the opinions of the U.S. Department of Health and Human Services, the Public Health Service, the Centers for Disease Control and Prevention, or the authors' affiliated institutions. 


\section{Table}

Table. Process of Planning and Implementing Lebanon Student Health Screenings, Lebanon, Pennsylvania, 2012-2013

\begin{tabular}{|c|c|c|c|c|c|c|c|c|c|}
\hline \multirow[b]{2}{*}{ Activity } & \multicolumn{7}{|c|}{2012} & \multicolumn{2}{|c|}{2013} \\
\hline & Jun & Jul & Aug & Sep & Oct & Nov & Dec & Jan & Feb \\
\hline Lebanon School District is identified as partner & $x$ & & & & & & & & \\
\hline PSHMC support for project is obtained & & $x$ & & & & & & & \\
\hline Lebanon School District support for project is obtained & & $x$ & & & & & & & \\
\hline $\begin{array}{l}\text { Planning meetings with Lebanon School District and PSHMC take } \\
\text { place }\end{array}$ & & $\mathrm{x}$ & $\mathrm{x}$ & $x$ & & & & & \\
\hline $\begin{array}{l}\text { PSHMC experts provide consultation for methodologically sound } \\
\text { screenings }\end{array}$ & & $\mathrm{x}$ & $\mathrm{x}$ & & & & & & \\
\hline PSHMC nurses are trained in screening methods & & & $x$ & & & & & & \\
\hline Schedules for staff and schools are developed & & & & $x$ & $x$ & & & & \\
\hline Screenings take place & & & & & & & $x$ & & \\
\hline Debrief meetings and follow-up surveys are completed & & & & & & & & $\mathrm{x}$ & $x$ \\
\hline
\end{tabular}

Abbreviation: PSHMC, Penn State Hershey Medical Center. 